\title{
AS PERCEPÇÕES DE IDOSOS FRENTE À ASSISTÊNCIA PRESTADA EM UMA INSTITUIÇÃO DE LONGA PERMANÊNCIA
}

\author{
Katiucia Silva de Oliveira ${ }^{1}$, Arlete Eli Kunz da Costa $^{2}$, Luis Felipe Pissaia ${ }^{3}$, \\ Claudete Moreschi ${ }^{4}$
}

Resumo: $\mathrm{O}$ objetivo desta pesquisa foi conhecer o atendimento que o idoso recebe pela equipe multiprofissional em uma instituição de longa permanência. Trata-se de um estudo descritivo com abordagem qualitativa realizado em uma Instituição de Longa Permanência do Vale do Taquari - RS. Os dados foram coletados entre março e abril de 2016 por meio de entrevistas semiestruturadas com dez usuários da instituição, sendo os mesmos submetidos a análise de dados conforme Bardin. Os dados obtidos apontam que os usuários estão satisfeitos com o atendimento oferecido na instituição, e o que favorece esta satisfação é a liberdade que eles têm de manifestar seus interesses. Conclui-se que o contentamento do idoso com a qualidade de vida está relacionado principalmente a fatores emocionais voltados á motivação para conviver. Evidencia-se que os idosos estão satisfeitos com suas vidas, mesmo que em certos momentos lamentam a ausência da família em visitas na instituição.

Palavras-chave:Idoso; Envelhecimento; Instituição de Longa Permanência; AssistênciaMultiprofissional; Humanização; Qualidade de Vida.

\section{PERCEPTIONS OF ELDERLY IN RELATION TO ASSISTANCE IN AN INSTITUTION OF LONG STAY}

\begin{abstract}
The objective of this research is to know the care that the elderly receive by the multidisciplinary team in a long-stay institution. This is a descriptive qualitative study carried out in a Long Term Care Institutions of the Taquari Valley - RS. Data were collected between March and April 2016 through semi-structured interviews with ten users of the institution's service, and they are bjected to data analysis according to Bardin. The data indicate that users are satisfied with the service offered in the institution,
\end{abstract}

1 Acadêmica do Curso de Enfermagem. Centro Universitário UNIVATES. katiucia.oliveira@unimedvtrp.com.br

2 Enfermeira. Mestre em Desenvolvimento Regional. Doutora em Ambiente e Desenvolvimento. Docente do Centro de Ciências Biológicas e da Saúde. Centro Universitário UNIVATES. arlete.costa@univates.br

3 Enfermeiro. Mestrando em Ensino. Centro Universitário UNIVATES. 1pissaia@universo.univates.br

4 Enfermeira. Mestre e Doutora em Ambiente e Desenvolvimento. Centro Universitário UNIVATES. clau_moreschi@yahoo.com.br 
and what prevails this satisfaction is the freedom they have to express their interests. The data indicate that users are satisfied with the service offered in the institution, and what prevails this satisfaction is the freedom they have to express their interests. It is evident that the elderly are satisfied with their lives, even if at times lament the absence of family visits in the institution.

Keywords: Elderly; Aging; Long-stay Institution; Multidisciplinary Care; Humanization; Quality of life.

\section{INTRODUÇÃO}

O envelhecimento tem seu início no momento da concepção e representa a passagem do tempo e não uma patologia em seu sentido literário, tratando-se de uma experiência singular e maravilhosa que possui notário e extraordinário valor no ciclo vital (KAUFFMAN, 2011). O processo de envelhecimento da humanidade é visto como um fenômeno complexo e vivenciado de diferentes maneiras pelas pessoas, de acordo com as condições intrínsecas, individuais e do ambiente onde estão inseridos (SILVA, 2012).

Pensar no envelhecimento da população tem se tornado algo cada vez mais presente no âmbito das discussões teóricas, dados apontam que no Brasil a população com mais de 60 anos teve um progresso significativo de $4 \%$ em 1940 para 8,6\% em 2000, sendo que a estimativa de vida ao nascer, em 1980 era de 57,2 anos para homens e de 64,3 para mulheres (BRASIL, 1994). Em 1990 esse número passou a ser 59,3 e 65,8 anos respectivamente, estimando-se que entre 2045 e 2050 a expectativa de vida do brasileiro seja de 76,9 anos de idade, ou seja, temos uma população idosa crescente (MORSCH et al., 2015).

Discussões acerca do presente tema vêm se desenvolvendo progressivamente e consecutivamente despertando interesse por estudos que indiquem alternativas possíveis e funcionais de apoio à população idosa (SILVA, 2012). Sendo assim, a partir da segunda metade do século, os estudos experimentais e clínicos aumentaram significativamente tornado o tema envelhecimento e idoso mais discutido e conhecido, principalmente nos países em desenvolvimento que até então não vivenciavam o envelhecimento de sua população, ao contrario dos países desenvolvidos (CARLI et al., 2012).

Evidenciando a importância da temática no contexto da população brasileira, em 4 de janeiro de 1994 foi aprovada a Lei no 8.842, que estabelece a Política Nacional do Idoso, posteriormente regulamentada pelo Decreto no 1948 de 1996, que reforça e introduz novas pautas de discussão além da legislação anterior (BRASIL, 1994). A referida Lei tem por finalidade assegurar direitos sociais que garantam a promoção da autonomia, integração e participação efetiva do idoso na sociedade, de modo a exercer a sua cidadania, considerando ainda em seu artigo segundo o idoso como toda a pessoa com sessenta anos ou mais de idade (KAUFFMAN, 2011).

Para que se estabeleça uma boa qualidade de vida na terceira idade é fundamental a inserção do idoso em atividades que desenvolvam suas habilidades e que oportunizem 
a sua participação enquanto ator social (CASTRO; DERHUN; CARREIRA, 2013). Neste contexto as comunidades possuem um papel fundamental enquanto agentes de mudança promovendo a seguridade do idoso em suas atividades, principalmente grupais mantendo e aumentando sua qualidade de vida (FERNANDES et al., 2015).

Além da sociedade, atualmente as famílias tem se deparado com a progressiva dificuldade em prestar a assistência necessária aos seus idosos em suas próprias residências, surgindo então os modelos de Instituições de Longa Permanência (ILPS) como uma crescente alternativa (MORSCH et al., 2015). Estas por sua vez desempenham papel de prestadoras de serviços de saúde com o propósito de favorecer as necessidades básicas do idoso, dentre elas, moradia, alimentação, convívio, cuidado integral à saúde, apoio social, judicial e administrativo (SILVA, 2012). Para a ANVISA na RDC no 283, de setembro de 2005, as ILPI's são Instituições governamentais ou não governamentais, de caráter residencial, destinada ao domicílio coletivo de pessoa com idade igual ou superior a 60 anos, com ou sem suporte familiar, em condições de liberdade, dignidade e cidadania (BRASIL, 2005).

Quando se trata de saúde, o trabalho desenvolvido nas ILPI ocorre por meio de uma equipe de profissionais, numa circunstância de trabalho coletivo, sendo a comunicação essencial ao estabelecimento de relações interpessoais e um denominador comum do esforço em equipe, o qual decorre da relação recíproca entre afazeres e interação (PEDUZZI, 2001). Deste modo, é fundamental que os profissionais atuantes nestas instituições reconheçam a importância de lidar com as relações interpessoais, pois elas interferem diretamente na qualidade da assistência prestada ao cliente (CARLI et al., 2012).

Neste sentido, quando falamos em trabalho em equipe, precisamos lembrar que este está inteiramente associado ao trabalho multiprofissional ou multidisciplinar, onde profissionais com diferentes especialidades trabalham em prol de um mesmo objetivo, o bem estar do indivíduo e seu contexto social (CASTRO; DERHUN; CARREIRA, 2013). Tal trabalho tem ligação direta com a interação e integração dos profissionais envolvidos, sendo a comunicação entre os profissionais primordial para o desenvolvimento do trabalho em equipe (FERNANDES et al., 2015).

As equipes precisam ter consciência de que o processo de envelhecimento é uma realidade próxima de todos e conforme o profissional se vincula ao mundo cultural dos indivíduos, o cuidar, se torna mais eficaz (LENARDT et al., 2006). Estes por sua vez precisam estar presentes como pessoas capazes de saber fazer o cuidado específico ao idoso, baseado nos modelos holísticos de atenção à saúde, desenvolvendo a capacidade de compreender e relacionar-se com o meio imposto (KAUFFMAN, 2011).

Sendo assim, o presente estudo teve como objetivo conhecer a assistência que o idoso recebe pela equipe multiprofissional em uma Instituição de Longa Permanência para Idosos, bem como as ações promovidas pela equipe que presta o cuidado. 


\section{METODOLOGIA}

Trata-se de uma pesquisa descritiva, exploratória e com abordagem qualitativa, realizada com dez idosos residentes em uma Instituição de Longa Permanência para Idosos localizada em um município do Vale do Taquari, região central do Rio Grande do Sul, Brasil.

A amostra de entrevistados foi estabelecida através de critérios de inclusão, ficando estabelecido à participação de indivíduos com idade igual ou superior a 60 anos e residentes há mais de seis meses na instituição. Realizou-se um levantamento das pessoas que contemplavam os critérios e dentre eles foram sorteados aleatoriamente dez indivíduos, aos quais foram explicados os objetivos da pesquisa e os critérios éticos que a norteiam e convidando-os a participar do estudo.

A coleta de dados ocorreu durante os meses de março e abril de 2016, sendo realizada conforme disponibilidade dos entrevistados e dos pesquisadores. As entrevistas tiveram sua realização em um espaço individual na própria estrutura física da instituição, buscando garantir a privacidade e sigilo das informações relatadas.

Foram aplicadas entrevistas individuais, com questionário semiestruturado desenvolvido pelos pesquisadores, sendo que todos participantes assinaram o Termo de Consentimento Livre e Esclarecido (TCLE) e seus nomes foram preservados por meio do uso de nomes aleatórios de flores. As entrevistas tiveram seus áudios gravados, transcritos e analisados conforme preconiza a Análise de Conteúdo de Bardin (2011).

A pesquisa foi aprovada pela instituição alvo de estudo, recebendo autorização pelo Comitê de Ética em Pesquisa (COEP) do Centro Universitário Univates, através da CAAE no 11992112.8.00005310. Foram respeitados também os aspectos éticos sobre pesquisas com seres humanos que contemplam a Resolução 466/2012 do Conselho Nacional de Saúde.

\section{RESULTADOS E DISCUSSÃO}

\section{Caracterizações dos sujeitos da pesquisa}

Quanto às características dos sujeitos da pesquisa, constatou-se que dos dez entrevistados, nove são do sexo feminino e um do sexo masculino. Quanto à faixa etária, os indivíduos possuíam idade entre a faixa dos 70 a 98 anos.

A partir da análise dos dados, as informações foram organizadas e agrupadas em conteúdos compatíveis, resultando em três categorias temáticas: (1) Percepções dos idosos quanto ao atendimento recebido pela equipe atuante na Instituição de Longa Permanência para Idosos; (2) Qualidade de vida oferecida aos idosos institucionalizados; 
e, (3) As percepções dos idosos quanto a possíveis melhorias nos processos de trabalho da equipe atuante na instituição de longa permanência.

\section{Percepções dos idosos quanto ao atendimento recebido pela equipe atuante na Instituição de Longa Permanência para Idosos}

A assistência prestada por uma ILPI demanda de trabalho em equipe, sendo essencialmente de cunho interdisciplinar e integrativo, para tanto esta interação interfere diretamente nas metodologias de cuidado empregadas, bem como os resultados assistenciais obtidos. De um modo geral todos os entrevistados sentem-se muito bem com o atendimento prestado na instituição, sentem-se felizes e acolhidos pelas equipes o que pode ser evidenciado pelos seguintes relatos:

"As meninas aqui são muito legais eles nos deixam alegres, felizes, fazem o trabalho cantando às vezes. Elas ajudam a gente a tomar banho, fazer as coisas do dia-a-dia e que nós não conseguimos mais. Isso faz toda a diferença onde a gente fica aqui”. (Azaleia)

"Toda ela muito boa, tanto as de azul como as de branco [...] inclusive quando abriu aqui a casa eu fui a terceira pessoa que veio pra cá e eu fui pra casa da minha irmã uma época, mas como eu caia muito eu voltei estou há dezoito anos aqui [...] é muito bom isso aqui, tudo e todos". (Cravo)

"Muito bom, é mesmo é muito bom, atendem bem as pessoas que ficam aqui morando, aquelas de branco nos cuidam muito bem [...] eu ajudo elas aqui a lava a louça, estou aqui a vinte e dois anos". (Crisântemo)

No momento em que o idoso passa a ser institucionalizado, da início a participação em um grupo social peculiar de pessoas, no qual são determinados papéis evidenciados por dependência da equipe multidisciplinar e espaço físico limitado á tal instituição (ROACH, 2003). Desta forma, o bom atendimento prestado pela equipe multiprofissional caracteriza um ponto de reconhecimento positivo para a instituição que deseje um atendimento de qualidade e satisfatório perante seus clientes e comunidade (MICHEL et al., 2012).

O reconhecimento do trabalho da equipe vem por meio dos relatos de que os profissionais atuam em conjunto uns com os outros, caracterizando um trabalho interdisciplinar em sua essência. Acreditam ainda que a presença de todos no local é importante devido à assistência que cada um realiza em prol dos clientes, principalmente os que demandam de maiores cuidados devido ao seu estado de saúde, conforme as falas a seguir:

"Eu já disse é uma equipe muito boa, elas são muito unidas, elas, as funcionarias são bem unidas e sempre alegres né, não se tem queixa, assim pra mim esta ótima, talvez pra outras que tem mais sensibilidade seja diferente". (Orquidea) 
"Muito boa, muito boa, toda atenção desde o pequeno até o grande [...] tem umas gurias que eu me dou um pouco mais, mas todas elas são boas, muito, muito boas [...] não tem queixa de nenbuma". (Cravo)

"A casa é muito boa, eu que optei de vir pra cá, porque os meus filhos estão todos casados, meus netos todos trabalham fora, estudam, eu morava sozinha, e pra que ficar sozinha? Acabei quebrando a perna, fiquei hospitalizada duas semanas e aqui cuidam muito bem de mim, percebo o entrosamento das meninas quando estão por aqui”. (Bromélia)

A equipe multidisciplinar quando atua unida demonstra segurança aos seus clientes e ao lidar com pessoas idosas tem a oportunidade singular de colocar em prática a arte do cuidar, ainda que muitos clientes não retribuam imediatamente, eles o fazem posteriormente quando percebem a equipe como responsável pelo cuidado oferecido (NOBREGA; ARRUDA, 2012). Deste modo, entende-se que os idosos representam uma clientela com demandas próprias, intrínseco ao processo de envelhecimento e, portanto, requer uma atenção especial, de uma equipe multiprofissional qualificada e sensível as suas solicitações (FERNANDES et al., 2015).

\section{Qualidade de vida oferecida aos idosos institucionalizados}

A qualidade de vida do ser humano possui diversas maneiras singulares de avaliação, sendo estritamente subjetiva e influenciada por fatores determinantes, como a etnia, cultura e meio social ao qual estão inseridos ou ao qual faziam parte. Para os idosos institucionalizados a qualidade de vida pode ser vivida através de uma assistência de qualidade e participação de atividades individuais e grupais que ofereçam distração e bem estar naquele ambiente, conforme as falas:

"É tudo muito bom, mas eu é que sou muito egocêntrica eu sou muito pra mim eu gosto de fazer minhas coisas, converso com os outros, mas e tem alguns que a casinha esta fora, ai sabe né eu acabo fazendo meu tricô, minhas palavras cruzadas, leio jornal, faço o que eu quero a hora que eu quero". (Bromélia)

"Gosto de tudo as coisas, ganho visita, tomo chimarrão [...] cada um faz o que quer o que eu posso dizer, eu me sinto bem aqui, aqui eu tenho tudo não me falta nada [...] a comida é boa, converso com as amigas, faço ginástica com a professora, olbo muita televisão, jogo carta". (Azaleia)

"Pois é, é tudo isso, a gente se sente bem [...] temos aula de recreação na semana. Agora eu não faço muito, eu tenho outras coisas pra fazer, faço as minhas costurinhas e eu já fiz agora recentes trabalhos de artesanato [...] aqui tem uma convivência boa, mais elas são mais assim, quase sempre dormem, tem outra visão [...] esquecem algumas coisas, não tem mais consciência das coisas, são poucas que tem consciência das coisas. Aqui tem de tudo, jogo de carta, recreação, bingo". (Orquídea) 
Estima-se que a necessidade de qualidade de vida e bem estar esteja mais aflorado durante a infância e a velhice do ser humano, em primeiro momento ainda criança a busca é por atividades que gerem prazer momentâneo, já durante o envelhecimento a perda de algumas funções essenciais a sua autonomia fazem com que a realização de tais atividades prazerosas dependa de terceiros (ROSSETO et al., 2012). Atualmente a maioria dos estudiosos desta área traz consigo a ideia de que atividades simples do dia a dia, como por exemplo, a realização de trabalhos manuais aumenta a qualidade de vida da população idosa, quando desenvolvido como algo subjetivo e irreverente, por meio do acompanhamento da equipe multiprofissional (SILVA; SANTOS, 2010).

Colaborando com estes autores grande parte dos entrevistados relataram gostar da realização de tais atividades recreativas, tendo isto como meio de sair da rotina e suprir a necessidade de sentir-se ocupado na instituição. A disposição da equipe em oferecer maneiras para o idoso sentir-se útil em seu meio institucionalizado condiciona a uma assistência integral e efetiva, facilitando a assistência no local, conforme as falas:

"Eu não gosto de fazer mais física, porque doem as pernas e fica muito dolorido depois [...] eu gosto fazer tapete e vendo aqui e ganho meu dinheiro, eu fiz a minha vida toda então as meninas me dão o material e eu faço". (Gerânio)

"Aqui tudo é muito livre cada um pode fazer o que gosta e a hora que gosta, quando não quer ficar na sala com os outros pode ficar no seu quarto sozinho, ou fazendo as minhas toalhas, que gosto muito, assim como quiser [...] eu às vezes jogo pife também". (Amor Perfeito)

"O que eu posso dizer, eu me sinto bem aqui, aqui eu tenho tudo não me falta nada [...] a comida é boa, converso com as amigas, faço ginástica com a professora, olho muita televisão, jogo carta e ainda me deixam fazer chinelos decorados para passar o tempo e dar de presente pras minhas filhas". (Azaleia)

A construção de peças artesanais pelos idosos institucionalizados dispõe de diversas peculiaridades presentes nestes espaços, desenvolvendo a utilização de criatividade, através da utilização de diversos materiais e elementos disponíveis no local, realizando a experimentação de suas próprias capacidades (KAUFFMAN, 2011). A disponibilidade do idoso em realizar trabalhos manuais é comprovada através de vários estudos como propicio para a concentração, aperfeiçoamento da destreza principalmente manual e como relaxante muscular, além de retratar parte de sua construção cultural vivida (MORSCH et al.,2015).

\section{As percepções dos idosos quanto a possíveis melhorias nos processos de trabalho da equipe atuante na instituição de longa permanência}

Uma ILPI, bem como qualquer serviço de saúde deve estar em constante aperfeiçoamento de sua estrutura física e de pessoal, buscando sempre refletir a capacidade de prestar uma assistência unificadora e efetiva ao cliente. Deste modo os entrevistados em sua maioria, mantiveram uma postura firme em relação aos quesitos 
que compõem os processos de trabalho da instituição, qualificando o trabalho oferecido, conforme as falas:

"Não sei o que te dizer, eu gosto do que tem aqui, todos me ajudam tudo o que fazem é bom pra mim". (Amor Perfeito)

"Não sei o que podia mudar, pra mim tanto faz porque tudo me serve bem [...] eu estou muito bem aqui [...] os filhos que vem pouco só, mas a equipe ajuda muito, eles que mantém a minha saúde”. (Azaleia)

"[...] a filha vem busca pouco, pega no domingo e já me entrega na segunda cedo, a filha podia vim mais. Com 82 anos não tem mais muita vontade pra fazer muita coisa, mas os lugares aqui são bem grandes e da para fazer trabalhos, conversar ou só ficar ali olbando que tudo é bonito". (Jasmim)

A equipe multiprofissional que presta o cuidado tem o compromisso de oferecer uma qualidade de vida adequada aos idosos, sendo que este atendimento deve suprir as necessidades básicas dos clientes e conforme verificado nas falas e condizente com vários estudos publicados o nível de qualidade e excelência das ILPI estão aumentando nas últimas décadas (LIMA et al., 2010). Os espaços citados pelos entrevistados que promovem à participação do idoso em atividades recreativas, de lazer, oficinas e realizar trabalhos manuais leva em consideração o comprimento das legislações especificas acima de tudo, oferecendo assim o princípio de seguridade ao indivíduo e sua família, por meio do contato múltiplo multiprofissional (MICHEL et al., 2012).

\section{CONSIDERAÇÕES FINAIS}

O estudo torna-se pertinente por evidenciar que os idosos na sua maioria estão satisfeitos com sua institucionalização e se sentem felizes, apesar de saberem das limitações físicas, já que os motivos para sua satisfação são situações de conforto, interação com outras pessoas, bem estar e a presença da família com maior comprometimento. Percebe-se a existência de graus de dependência entre as pessoas residentes na instituição, o que retrata as diferentes demandas de assistência requeridas atualmente, ao passo que, os idosos independentes possuem mais iniciativa, assim como viabilidade de conservação de suas capacidades orgânicas.

Verificou-se que o trabalho da equipe multiprofissional agrega conhecimento e divide as inquietações, possibilitando, desta forma, a manifestação de soluções e, todo o trabalho realizado, favorecendo a promoção de uma melhoria na qualidade de vida dos usuários. Neste sentido passa o profissional a ser o responsável pela melhoria da qualidade da assistência do cliente, quando o trabalho é desenvolvido por pessoas que gostam do que fazem reflete inteiramente na satisfação do indivíduo.

O engajamento da equipe em prol dos usuários é fortemente percebido, uma vez que estes reconhecem o papel da equipe e a sua inserção nas atividades do dia a dia. A equipe 
preocupada com o bem estar desenvolve atividades de recreação, físicas e manuais, além de visitas da comunidade em geral com apresentações, entre outras diversas programações. Para tanto, as contribuições científicas deste estudo compreendem a atuação da equipe multiprofissional como necessárias visto a qualificação da assistência oferecida pela ILPI, sob o ponto de vista de seus clientes.

\section{REFERÊNCIAS}

BARDIN, L. Análise de conteúdo. 70. ed. São Paulo: Edições, 2011.

BRASIL. Lei n. 8.842, de 4 de janeiro de 1994. Dispõe sobre a política nacional do idoso, cria o conselho Nacional do Idoso e dá outras Providências. Disponível em: <http://www. planalto.gov.br/ccivil_03/leis/18842.htm>. Acesso em: 31 jan. 2016.

BRASIL. RDC n. 238, de 26 de setembro de 2005. Dispõe sobre o funcionamento das Instituições de Longa Permanência para Idosos. Brasília, DF. Disponível em: <http://bvsms. saude.gov.br/bvs/saudelegis/anvisa/2005/res0283_26_09_2005.html>. Acesso em: 31 jan. 2016.

CARLI, L. et al. Sentimentos e percepções de idosos residentes em uma Instituição Asilar. Revista de Pesquisa: Cuidado é fundamental online, v. 4, n. 2, p. 2868-2877, abr./jun. 2012.

CASTRO, V. C.; DERHUN, F. M.; CARREIRA, L. Satisfação dos Idosos e profissionais de enfermagem com o cuidado prestado em uma Instituição Asilar. J. res. fundam. care, v. 5, n. 4, p. 493-502, out./dez. 2013.

FERNANDES, H.N. et al. Relacionamento interpessoal no trabalho da equipe multiprofissional de uma unidade de saúde da família. Rev. pesqui. cuid. fundam., v. 7, n. 1, p. 1915-1926, jan./mar. 2015.

KAUFFMAN, T. L. Manual de reabilitação geriátrica. Rio de Janeiro: Guanabara Koogan S. A., 2011.

LENARDT, M. H. et al. O Idoso institucionalizado e a cultura de cuidados profissionais. Cotigare Enferm, v. 11, n. 2, p. 117-123, maio/ago. 2006.

LIMA, T. J. V. et al. Humanização na Atenção à saúde do Idoso. Saúde Soc., São Paulo, v. 19, n. 4, p. 866-877, 2010.

MICHEL, T. et al. Significados atribuídos pelos idosos á vivência em uma instituição de longa permanência: contribuições para o cuidado de enfermagem. Texto Contexto Enferm, Florianópolis, v. 21, n.3, p. 495-504, jul./set. 2012.

MORSCH, P. et al. Características clínicas e sociais determinantes para o idoso sair de casa. Cad. Saúde Pública, Rio de Janeiro, v. 31, n. 5, maio 2015.

NÓBREGA, I. R. A.; ARRUDA, F. G. Residência multiprofissional em Saúde do Idoso: relatando experiências à luz da Política Nacional da Humanização. Revista Portal de divulgação, n. 27, ano III, nov. 2012. 
PEDUZZI, M. Equipe multiprofissional de saúde: Conceito e tipologia. Rev Saúde Pública, São Paulo: USP 2001.

$\mathrm{ROACH}$, S. Introdução a enfermagem Gerontológica. Rio de Janeiro: Guanabara Koogan S. A., 2003.

ROSSETTO, M. et al. Depressão em idosos de uma Instituição de Longa Permanência. Rev. Enferm., UFSM, v. 2, n. 2, p. 347-352, maio/ago. 2012.

SILVA, B.T.; SANTOS, S. S. C. Cuidados aos idosos institucionalizados - opiniões do sujeito coletivo enfermeiro para 2026. Acta Paul Enferm., v. 23, n. 6, p. 775-781, 2010.

SILVA, J. V. Saúde do Idoso: Processo de envelhecimento sob múltiplos aspectos. 1. ed. São Paulo: Iátria, 2012. 